\title{
TOTAL HIP REPLACEMENT FOR JUVENILE CHRONIC ARTHRITIS
}

\author{
J. D. WITT, M. SWANN, B. M. ANSELL
}

From Wexham Park Hospital, Slough, England

\begin{abstract}
We review the results of 96 primary total hip replacements in 54 patients with juvenile chronic arthritis at five years or longer after surgery. The mean age at operation was 16.7 years (range 11.25 to 26.6); the follow-up period averaged 11.5 years. The clinical results in terms of pain, range of movement, mobility and function are presented. A revision procedure was required in 24 hips (25\%) in 18 patients at an average of 9.5 years after the primary operation. A further 17 hips had radiographic signs of loosening. The factors thought to contribute to this relatively high failure rate in patients with juvenile chronic arthritis are discussed.
\end{abstract}

The benefits of total hip arthroplasty in patients with juvenile chronic arthritis are well documented (Halley and Charnley 1975; Bisla, Inglis and Ranawat 1976; Colville and Raunio 1979; Arden 1983; Ruddlesdin et al 1986). What is less certain is the long-term results and subsequent problems of loosening and revision surgery which are probably inevitable in these cases. We report the results of primary total hip arthroplasty in patients with juvenile chronic arthritis with a minimum five year follow-up.

\section{PATIENTS AND METHOD}

Between 1969 and 1984, 67 patients under the age of 27 years underwent 118 total hip arthroplasties for juvenile chronic arthritis at Wexham Park Hospital, Slough or Heatherwood Hospital, Ascot. Of this group, four patients died from the complications of amyloid disease and nine patients were lost to follow-up, leaving 54 patients with 96 arthroplasties to review. Ruddlesdin et al reported on 29 of these patients in 1986.

One or other of the authors examined 49 of the patients and in five cases the clinical and radiographic information was obtained from the patients' current orthopaedic surgeon. The average length of follow-up was 11.5 years (range 5.3 to 18.3 ). In $62.5 \%$ of cases the follow-up period was ten years or longer. There were 51

J. D. Witt, FRCS, Senior Orthopaedic Registrar

King's College Hospital, Denmark Hill, London SE5 9RS, England.

M. Swann, FRCS, Consultant Orthopaedic Surgeon

B. M. Ansell, $C B E, M D$, FRCS, FRCP, Consultant Rheumatologist

Wexham Park Hospital, Slough, Berkshire SL2 4HL, England.

Correspondence should be sent to Mr M. Swann.

(C) 1991 British Editorial Society of Bone and Joint Surgery

$0301-620 X / 91 / 5191 \$ 2.00$

J Bone Joint Surg [ Br] 1991 ; 73-B: 770-3. women and three men. The average age at surgery was 16.75 years (range 11.25 to 26.6). Both hips had been replaced in 42 patients. The mean interval between the onset of arthritis and surgery was 11.5 years. The mean interval between symptoms of hip involvement and hip replacement was 3.6 years. In $22 \%$ of patients the onset of arthritis was systemic, $48 \%$ were sero-positive and polyarticular, $22 \%$ were sero-negative and polyarticular and $8 \%$ were pauciarticular.

Operative technique. Prior to surgery each child was assessed by a team which included a paediatric rheumatologist, an orthopaedic surgeon, an anaesthetist, a nurse, a physiotherapist and an occupational therapist. The operations were performed by several surgeons. Usually a lateral approach was employed, with or without trochanteric osteotomy. A variety of prostheses were used, the majority being McKee-Arden (60\%) but $11 \%$ were custom-made implants. All were cemented with methylmethacrylate. Prophylactic antibiotics were given routinely in the peri-operative period. Suction drains were removed 48 hours after operation and the patients were allowed to walk with support on the third day. The anaesthetic problems that may be encountered have been reported (Ruddlesdin et al 1986). Patients were seen postoperatively by one or other of the authors at three months, six months and then at yearly intervals. The hips were graded before surgery and at follow-up, using the scoring system of the Hospital for Special Surgery (Salvati and Wilson 1973).

\section{RESULTS}

The pain relief afforded by the operation is clear from the results recorded in Table $I$. The average pain grade pre-operatively was 1.3 and the average grade at followup was 8.6 , a mean improvement of 7.3 points.

Table II shows the improvement in the range of movement of the affected hips following surgery. The 
Table I. Pain before operation and at follow-up, five hips with a Girdlestone procedure at review are excluded

\begin{tabular}{|c|c|c|c|}
\hline \multirow[b]{2}{*}{ Grade } & \multirow[b]{2}{*}{ Description of pain } & \multicolumn{2}{|c|}{ Number of hips } \\
\hline & & Pre-op & At review \\
\hline 0 & All the time - unbearable & 37 & 0 \\
\hline 2 & $\begin{array}{l}\text { All the time - bearable - } \\
\text { regular analgesia }\end{array}$ & 48 & 0 \\
\hline 4 & $\begin{array}{l}\text { None or little at rest - } \\
\text { moderate on activity }\end{array}$ & 6 & 9 \\
\hline 6 & $\begin{array}{l}\text { Moderate on commencing } \\
\text { activity, then easing }\end{array}$ & 0 & 5 \\
\hline 8 & Occasional and slight & 0 & 26 \\
\hline \multirow[t]{2}{*}{10} & None & 0 & 51 \\
\hline & Total & 91 & 91 \\
\hline
\end{tabular}

Table II. Range of movement of affected hips before operation and at follow-up, five hips with a Girdlestone procedure at review are excluded

\begin{tabular}{llcc}
\hline & & \multicolumn{2}{c}{ Number of hips } \\
\cline { 3 - 4 } Grade & Flexibility & Pre-0p & At review \\
\hline 0 & Ankylosis with deformity & 13 & 0 \\
2 & Ankylosis in functional position & 4 & 0 \\
4 & Flexion $<60^{\circ}$, abduction restricted & 65 & 8 \\
6 & Flexion $90^{\circ}$, abduction $10^{\circ}$ to $20^{\circ}$ & 9 & 62 \\
8 & Flexion $>90^{\circ}$, abduction $>20^{\circ}$ & 0 & 19 \\
10 & Normal movement & 0 & 2 \\
& Total & 91 & 91 \\
\hline
\end{tabular}

Table III. Mobility of patients before operation and at follow-up, three patients with a Girdlestone procedure at review are excluded

\begin{tabular}{llcc}
\hline & & \multicolumn{2}{c}{ Number of patients } \\
\cline { 3 - 4 } Grade & Mobility & Pre-op & At review \\
\hline 0 & Bedridden & 0 & 0 \\
2 & Wheelchair & 27 & 1 \\
4 & $\begin{array}{l}\text { Walks without support - } \\
\text { housebound } \\
\text { With support < 100 yards }\end{array}$ & 15 & 9 \\
6 & $\begin{array}{l}\text { Walks without support < 25 yards } \\
\text { With support < 1 mile }\end{array}$ & 9 & 12 \\
8 & $\begin{array}{l}\text { Walks without support - } \\
\text { unrestricted, but with a limp }\end{array}$ & 0 & 26 \\
10 & $\quad$ Normal & 0 & 3 \\
\hline
\end{tabular}

average pre-operative grade was 3.8 and the average grade at follow-up was 6.3 , a mean improvement of 2.5 points.

Table III shows the improvement in mobility following hip surgery. Prior to operation 27 patients were confined to wheelchairs, whereas only one patient
Table IV. Functional grading of patients before operation and at follow-up, three patients with a Girdlestone procedure at review are excluded

\begin{tabular}{lllc}
\hline & & \multicolumn{2}{c}{ Number of patients } \\
\cline { 3 - 4 } Grade & Function & Pre-op & At review \\
\hline 0 & Completely dependent & 20 & 0 \\
2 & Partially dependent & 25 & 6 \\
4 & Independent - limited housework & 3 & 5 \\
6 & $\begin{array}{l}\text { Independent - most housework - } \\
\text { sedentary job }\end{array}$ & 3 & 17 \\
8 & Little restriction - ambulatory job & 0 & 21 \\
10 & Normal activities & 0 & 2 \\
& Total & 51 & 51 \\
\hline
\end{tabular}

remained chairbound at follow-up. The average grade before operation was 3.3 and the average grade at review was 6.8 , a mean improvement of 3.5 points.

Although the majority of patients had polyarticular involvement, hip replacement surgery resulted in a considerable improvement in their overall functional capability. The results are shown in Table IV. The average pre-operative score was 1.6 and the average score at follow-up was 6.3 , a mean improvement of 4.7 points.

Three patients were attending school or college; 32 were employed mainly in sedentary occupations, either part-time or full-time; five were involved with voluntary work for the disabled. Driving was considered to be an important indicator of independence; 37 patients drove regularly. In one case the car was specially adapted, another drove an invalid vehicle but the remaining 35 patients required no adaption of their cars apart from automatic transmission. Sixteen of the women have married; five of them have given birth to one child, and three to two children; one man has married.

Complications. A revision procedure was required in 24 hips in 18 patients at an average of 9.5 years after the primary operation (range 1 to 14). The reasons for failure and the subsequent operations are shown in Table $\mathrm{V}$.

Table V. Reason for failure and subsequent operation

\begin{tabular}{lc}
\hline Stem loose - revision & $\begin{array}{c}\text { Number of } \\
\text { procedures }\end{array}$ \\
Cup loose - revision & 3 \\
Cup and stem loose - revision & 5 \\
Infection - conversion to Girdlestone & $12^{*}$ \\
Cup and stem loose - conversion to Girdlestone & 3 \\
Fractured shaft of femur - revision & $2 \dagger$ \\
\hline
\end{tabular}

*in one patient the cup was revised ten months before the stem was replaced the revised hip in one patient loosened and was then converted to a Girdlestone

fone patient fractured his femur four weeks after a revision for loosening and therefore had a second procedure 
Two hips had more than one revision procedure. In one, the revised hip loosened with no evidence of infection and was converted to a Girdlestone 22 months later; in the second case a revision had been performed for aseptic loosening and four weeks later the patient fell, fracturing the femur around the tip of the prosthesis (Fig. 1); this was revised using a long stem femoral component (Fig. 2).

The average age at the time of revision surgery was 25.7 years (range 17 to 31 ). A breakdown of the time until revision in the 24 cases is given in Figure 3.

There was one case of common peroneal nerve palsy following operation; it recovered fully over a period of 12 months.

Radiographic analysis. Radio-opaque cement was not used in the early operations in this series. However, an attempt was made to determine the incidence of loosening in the remaining 72 patients who had not undergone revision. Endosteal bone resorption and migration of components were taken as indicators of loosening and impending failure. Migration of components was assessed by superimposition of the postoperative radiograph on that taken at the most recent follow-up examination. A change in position of the components, seen on serial radiographs in 17 cases, was considered evidence of loosening. Signs of migration of the cup were seen in four patients, and in another four, of the stem. In two cases both components showed signs of migration. Endosteal erosion was seen around the cup in one case and around the stem in two. Signs of both migration and endosteal erosion were seen to affect the cup in one hip, the stem in one hip and both components in two. Only the two hips with both components showing evidence of migration and endosteal erosion were symptomatic.

\section{DISCUSSION}

The benefit of hip surgery has been well maintained over the follow-up period. One patient expressed disappointment at having had a hip replacement; the remainder were enthusiastic about their improvement. Although the majority had polyarticular involvement, the effect of hip replacement on overall mobility and function is well demonstrated, despite the fact that the hip rating scale does not take into account the effect of other joint involvement on these parameters.

There have been several reports on the failure rate of total hip replacement in young people. Chandler et al (1981) reported a $9 \%$ revision rate in 33 replacements in patients under 30 years with an average follow-up of 5.6 years. Radiographic examination, however, revealed that $57 \%$ showed actual or potential signs of loosening. Dorr, Takei and Conaty (1983) reported a revision rate of $11 \%$ of 108 hip replacements in patients under 45 years of age, followed for an average of 4.5 years. The revision rate in 43 of the hips followed for an average of 6.5 years was $19 \%$. The majority of patients in these studies had

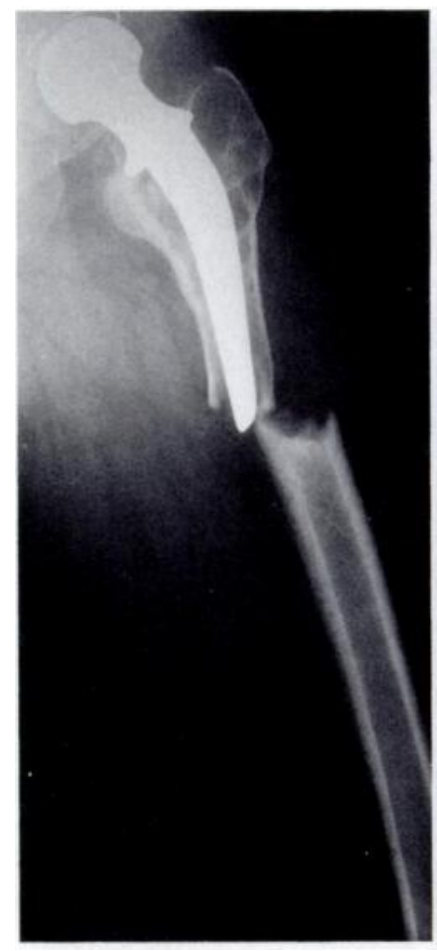

Fig. 1

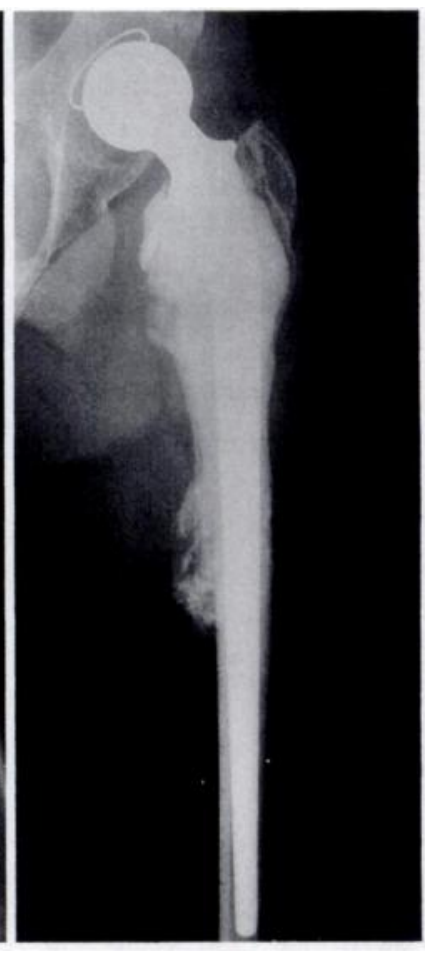

Fig. 2
Figure 1 - Fracture at the tip of a recently revised prosthesis. Figure 2 - Conversion with a long stem component.

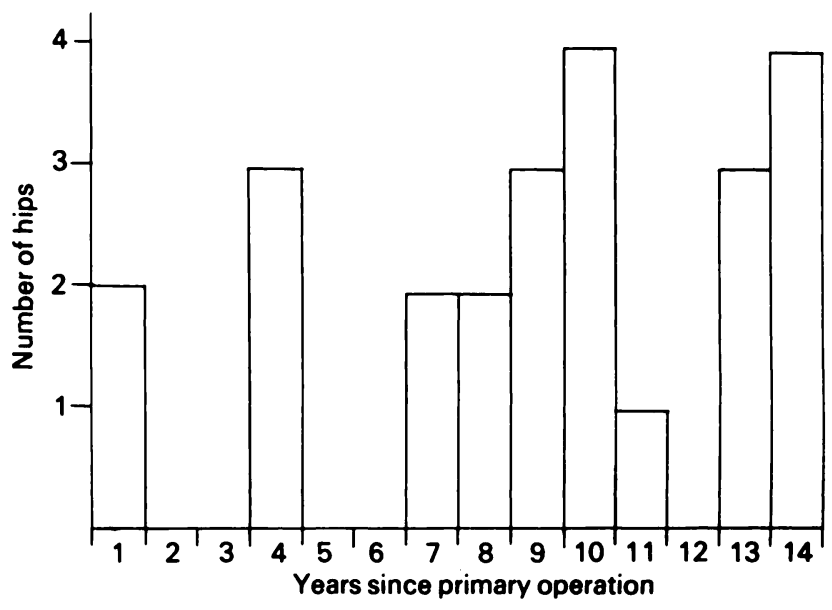

Fig. 3

Length of time to revision surgery in 24 hips.

monoarticular involvement and therefore a relatively high physical activity level, accounting to a large extent for these results.

Early results of total hip replacement in patients with juvenile chronic arthritis were encouraging with regard to failure rate. Bisla et al (1976) reported 67 total hip replacements in 45 patients under 30 years of age; 26 of these had juvenile rheumatoid arthritis. There were no revisions after an average follow-up of 2.7 years; however, there were radiolucent lines around the acetabular components in 38 hips. Singsen et al (1978) reported 26 
hip replacements for juvenile chronic arthritis in 14 children aged between 12 and 14 years. Our results with regard to the relief of pain and improvement in range of movement agree with theirs. They reported no failures but the follow-up time was short (mean 2.2 years). Colville and Raunio (1979) reported 59 total hip replacements in 41 patients with juvenile rheumatoid arthritis. The average age at the time of surgery was 30.5 years and after a mean follow-up period of 2.5 years, there was no case of loosening. Scott, Sarokhan and Dalziel (1984) reported 64 total hip replacements in 55 patients with juvenile chronic arthritis. After a mean follow-up of five years, four $(7 \%)$ had been revised for loosening.

More recently there have been reports suggesting that the revision rate may be considerably higher than would be expected considering the small stature of these patients and their relatively low level of physical activity. Roach and Paradies (1984) reported a small series in which one third had been revised for symptomatic loosening, and similar experience was reported by Lachiewicz et al (1986) and Learmonth et al (1989).

In the series from this unit, reported by Ruddlesdin et al (1986) there was only one acetabular revision after a period of 5.4 years (mean). The current review demonstrates that 24 of 96 hip replacements $(25 \%)$ failed at an average of 9.5 years. In addition, a further 17 hips showed radiographic signs of loosening and seven hips, signs of endosteal erosion. However, this probably underestimates the incidence of radiolucent lines which would have been seen, had radio-opaque cement been used. Migration of one or both components was seen in ten hips with no sign of bone resorption. These hips were symptomless and represent arrested loosening (Gruen, McNeice and Amstutz 1979). In those cases in which both endosteal bone resorption and migration were present, two out of four were symptomatic. This was thought to represent fragmentation of the cement and impending failure.

It would appear that factors other than body-weight and physical activity are contributing to a high failure rate in patients with juvenile chronic arthritis. The degree of osteoporosity is influenced by disease activity and the bone is frequently highly vascular, compromising the cementing technique. The majority of patients $(60 \%)$ were on steroids at the time of operation and the relatively low level of physical activity of these patients also contributes to the osteoporosis. The poor quality of bone may make these patients unsuitable for uncemented implants, although this remains to be studied. Perhaps the use of customised implants, which allow a more uniform cement mantle, may improve results.

The local anatomy of the hip is often severely deranged by a combination of soft-tissue contractures and bone deformity making surgery more difficult and causing greater stresses on the new hip. These may be exacerbated when adjacent joints, lumbar spine and knees, are also stiff as is commonly the case.

The incidence of infection was low in this series considering the immunocompromised state of most patients. All wounds healed by first intention. Deep infection led to failure in four hips, two of which were in one patient, at ten years, and attributable to persistent sacral decubitus ulcers.

The undoubted success of hip replacement surgery with regard to the quality of life should not diminish the caution that must be exercised in recommending hip replacements in these young people. It is hoped that the long-term results will improve with the use of customised implants and better cementing techniques. In addition greater understanding of the process by which the disease affects bone stock may lead to preventive or therapeutic remedies.

No benefits in any form have been received or will be received from a commercial party related directly or indirectly to the subject of this article.

\section{REFERENCES}

Arden GP. Surgical treatment of Still's disease: (juvenile chronic arthritis). Ann Acad Med Singapore 1983; 12:174-84.

Bisla RS, Inglis AE, Ranawat CS. Joint replacement surgery in patients under thirty. J Bone Joint Surg [ Am] 1976; 58-A:1098-104.

Chandler HP, Reineck FT, Wixson RL, McCarthy JC. Total hip replacement in patients younger than thirty years old: a five-year follow-up study. J Bone Joint Surg [ Am] 1981; 63-A:1426-34.

Colville J, Raunio P. Total hip replacement in juvenile chronic arthritis: analysis of 59 hips. Acta Orthop Scand 1979; 50:197-203.

Dorr LD, Takei GK, Conaty JP. Total hip arthroplasties in patients less than forty-five years old. J Bone Joint Surg [Am] 1983; 65-A:4749.

Gruen TA, McNeice GM, Amstutz HC. “Modes of failure” of cemented stem-type femoral components: a radiographic analysis of loosening. Clin Orthop 1979; $141: 17-27$.

Halley DK, Chamley J. Results of low friction arthroplasty in patients thirty years of age or younger. Clin Orthop 1975; 112:180-91.

Lachiewicz PF, McCaskill B, Inglis AE, Ranawat CS, Rosenstein BD. Total hip arthroplasty in juvenile rheumatoid arthritis: two to eleven year results. J Bone Joint Surg [ Am] 1986; 68-A :502-8.

Learmonth ID, Heywood AWB, Kaye J, Dall D. Radiological loosening after cemented hip replacement for juvenile chronic arthritis. $J$ Bone Joint Surg [Br] 1989; 71-B:209-12.

Roach JW, Paradies LH. Total hip arthroplasty performed during adolescence. J Pediatr Orthop 1984; 4:418-21.

Ruddlesdin C, Ansell BM, Arden GP, Swann M. Total hip replacement in children with juvenile chronic arthritis. $J$ Bone Joint Surg [Br] $1986 ; 68-B: 218-22$.

Salvati EA, Wilson PD Jr. Long-term results of femoral-head replacement. J Bone Joint Surg [Am] 1973; 55-A :516-24.

Scott RD, Sarokhan AJ, Dalziel R. Total hip and knee arthroplasty in juvenile rheumatoid arthritis. Clin Orthop 1984; $182: 90-8$.

Singsen BH, Isaacson AS, Bernstein BH, et al. Total hip replacement in children with arthritis. Arthritis Rheum 1978; $21: 401-6$. 